\title{
Neurons and astrocytes of the chicken hypothalamus directly respond to lipopolysaccharide and chicken interleukin-6
}

\author{
Niklas Grabbe ${ }^{1} \cdot$ Bernd Kaspers $^{2} \cdot$ Daniela Ott $^{1} \cdot$ Jolanta Murgott $^{1} \cdot$ Rüdiger Gerstberger $^{1} \cdot$ Joachim Roth $^{1}$
}

Received: 8 April 2019 / Revised: 22 October 2019 / Accepted: 8 December 2019 / Published online: 21 January 2020

(c) The Author(s) 2020

\begin{abstract}
In 4-5-month-old chicken, intravenous injections of bacterial lipopolysaccharide (LPS) induced a dose-dependent fever response and a pronounced increase of circulating interleukin-6 (IL-6). To assess a possible role for IL-6 in the brain of birds, a hypothalamic neuro-glial primary culture from 1-day-old chicken was established. Each well of cultured hypothalamic cells contained some 615 neurons, 1350 astrocytes, and 580 microglial cells on average. Incubation of chicken hypothalamic primary cultures with 10 or $100 \mu \mathrm{g} / \mathrm{ml}$ LPS induced a dose-dependent release of bioactive IL-6 into the supernatant. Populations of hypothalamic neurons (4\%) and astrocytes (12\%) directly responded to superfusion with buffer containing $10 \mu \mathrm{g} /$ $\mathrm{ml}$ LPS with a transient increase of intracellular calcium, a sign of direct cellular activation. Stimulation of hypothalamic cultures with buffer containing $50 \mathrm{ng} / \mathrm{ml}$ chicken IL-6 induced calcium signaling in $11 \%$ of neurons and $22 \%$ of astrocytes investigated. These results demonstrate that IL- 6 is produced in the periphery and in the hypothalamus in response to LPS in chicken. The observed cellular responses of hypothalamic cells to chicken IL-6 indicate that this cytokine may readily be involved in the manifestation of fever in the avian hypothalamus.
\end{abstract}

Keywords Chicken $\cdot$ Fever $\cdot$ Interleukin- $6 \cdot$ Hypothalamus $\cdot$ Primary neuro-glial culture $\cdot$ Lipopolysaccharide $\cdot$ Calcium imaging

\section{Introduction}

Most experimental studies dealing with the genesis of fever were performed in mammals, such as rabbits, rats, mice, or guinea pigs (Kluger 1991; Roth and Blatteis 2014). Much less investigations were performed in birds, the second class of homeothermic vertebrates (Gray et al. 2013). There are striking differences between both classes with regard to some specific properties of their thermoregulatory systems, namely hypothalamic thermosensitivity to cold stimulation (Simon et al. 1986; Bicego et al. 2007). In the majority of laboratory studies, lipopolysaccharide (LPS)

Communicated by Fritz Geiser.

Joachim Roth

Joachim.Roth@vetmed.uni-giessen.de

1 Institute of Veterinary Physiology and Biochemistry, JustusLiebig-University, Frankfurter Strasse 100, 35392 Gießen, Germany

2 Department of Veterinary Science, Ludwig-Maximilians-Uni versity, Veterinärstrasse 13, Munich, Germany from Gram-negative bacteria has been used as the exogenous inducer ("exogenous pyrogen") of a febrile response in mammals and birds. In mammals, the patterns of body core temperature $\left(T_{\mathrm{b}}\right)$ changes in response to LPS depend on the injected dose of LPS and on ambient temperature. High LPS doses and low ambient temperature favor the manifestation of a hypothermic phase prior to a febrile increase of $\mathrm{T}_{\mathrm{b}}$ above its normal values (Töllner et al. 2000; Romanovsky et al. 2005; Rudaya et al. 2005; Garami et al. 2019). In addition, shape and magnitude of a given febrile response depend on the phase of the circadian rhythm, in which the pyrogen is injected (Luker et al. 2000). Some of these features of mammalian fever are also observed in birds. For example, in pigeons, the amplitude of LPS-induced fever is much higher, when the pyrogen is injected in the dark phase when their $T_{\mathrm{b}}$ is low (Nomoto 1996). Injection of a very high dose of LPS $(2.5 \mathrm{mg} / \mathrm{kg})$ caused hypotension and a short hypothermic response in chicken (De Boever et al. 2009). LPS injected at daytime in Pekin ducks induced dose-dependent monophasic fevers (Maloney and Gray 1998), which are attenuated at cold ambient temperature (Gray et al. 2013). With a few exceptions, the mechanisms responsible for the 
manifestation of fever have been investigated in mammals. The action of prostaglandin $\mathrm{E}_{2}\left(\mathrm{PGE}_{2}\right)$ on neurons within the preoptic-anterior hypothalamic area (POA) is regarded as the final step for the induction of mammalian fever. It was suggested that peripherally generated $\mathrm{PGE}_{2}$ is involved in the early onset of the febrile response due to its transport across the blood-brain barrier (BBB) into the hypothalamus (Steiner et al. 2006; Saper et al. 2012) or via the stimulation of afferent nerves (Li et al. 2006; Roth and Blatteis 2014). The longer lasting later phases of fever are mediated by brain-intrinsic formation of $\mathrm{PGE}_{2}$, predominantly produced by endothelial cells within the POA (Saper et al. 2012; Eskillson et al. 2017). The formation of $\mathrm{PGE}_{2}$ within the brain, in turn, is mediated by the appearance of tumor necrosis factor- $\alpha$ (TNF- $\alpha$ ), interleukin- $1 \beta$ (IL-1 $\beta)$, interleukin-6 (IL-6), and other cytokines in the systemic circulation of LPS-treated mammalian species. Within this cytokine cascade, TNF- $\alpha$ represents the initial mediator, followed by rather small amounts of IL- $1 \beta$, and a pronounced and prolonged presence of IL-6 in the blood (Kluger 1991; Jansky et al. 1995; Li et al. 2006). The prolonged presence of IL-6 in the blood after injection of LPS, its close correlation to febrile changes of $T_{\mathrm{b}}$, and the lack of fever in IL-6-deficient mice made this cytokine an excellent candidate as an essential endogenous pyrogen (Kluger 1991; Chai et al. 1996; Kozak et al. 1998; Cartmell et al. 2000). A critical question in this context is how the hydrophilic cytokine IL-6 might reach the thermoregulatory relevant hypothalamic structures in the brain to induce neuronal changes, which are consistent with a regulated $T_{\mathrm{b}}$ increase. There is some evidence that IL-6 might reach the brain via circumventricular organs, where the BBB is incomplete (Harré et al. 2002). More recently, an alternative LPS or IL-6 mediated inflammatory signal transfer from the blood into the brain was suggested. According to this hypothesis, endothelial cells within the POA are directly activated by circulating LPS and/or IL-6 (Rummel et al. 2005, 2006; Eskillson et al. 2014). Due to the transfer of inflammatory signals across the BBB, a second wave of the pyrogenic cytokine IL-6 is produced locally within the hypothalamus (Klir et al. 1993; Jansky et al. 1995) and might directly or via formation of $\mathrm{PGE}_{2}$ influence neurons involved in thermoregulation. A role for central IL-6 in the manifestation of fever in mammals is well established (Lenczowski et al. 1999). A localized production of IL-6 within the hypothalamus might, therefore, also be a critical step in the manifestation of LPS-induced fever in birds.

Previous studies on mammalian neuro-glial primary cultures from hypothalamus and OVLT showed that these structures have the capacity to produce significant amounts of IL-6 upon inflammatory stimulation (Simm et al. 2016). Notably, direct cellular responses in cultures of these mammalian brain sites upon stimulation with LPS or species-specific IL-6 could be demonstrated (Ott et al. 2010). The central goal of the present study was, therefore, to establish and investigate a neuro-glial primary culture of the chicken hypothalamus. The capacity of this culture to produce IL-6 after exposure to LPS was determined. Measurements of stimulus-induced $\mathrm{Ca}^{2+}$-signals were applied to investigate cellular responses of this culture to LPS or chicken IL-6. In vivo studies showed that pattern and duration of LPS-dependent fever in chicken strongly depend on the injected dose of LPS.

\section{Materials and methods}

\section{Animals}

4-5-month-old female chicken were used for in vivo experiments (Lohmann Poultry Breeding, Gut Heinrichsruh, Berglern, Germany). One day old male and female chicken were obtained from an in house breeding (Clinic for Birds, Reptiles, Amphibians and Fishes, Justus-Liebig-University of Gießen). Animal care, breeding, and experimental procedures were performed according to the guidelines approved by the Bavarian and Hessian Ethical Committees (approval numbers Munich 209.1/211-2531-46/03 and Giessen 680_M). Chicken for in vivo experiments were held under an artificial light-dark cycle. Lights were on between 6:00 and 20:00 $\mathrm{h}$ and room temperature was $22 \pm 1{ }^{\circ} \mathrm{C}$.

\section{In vivo experiments}

Under isoflurane inhalation anesthesia, a temperature data logger (SubCue, Calgary, Canada) was implanted into the abdominal cavity to measure $T_{\mathrm{b}}$ of chicken. Isoflurane was administered via a face mask at an initial concentration of $5 \%$ and a maintenance concentration of up to $3 \%$. Meloxicam (Boehringer Ingelheim, Germany) was intramuscularly injected as analgesic at a dose of $0.5 \mathrm{mg} / \mathrm{kg} 1 \mathrm{~h}$ prior to surgery and two times per day at the following 2 days. Anesthesia and analgesia were performed according to veterinary practice for birds (Erhardt et al. 2011).

$T_{\mathrm{b}}$ was continuously recorded at 15 -min intervals. At least 1 week after surgery, phosphate-buffered saline (PBS, PAA, Cölbe, Germany) or lipopolysaccharide (LPS; SigmaAldrich, Taufkirchen, Germany) was injected into the jugular vein. Different doses of LPS (10 ng/kg $-1 \mathrm{mg} / \mathrm{kg} ; N=3$ per group) were injected intravenously at $18 \mathrm{~h}$ immediately prior to the start of the lights-off period to test the effects on $T_{\mathrm{b}}$. In an additional experiment in chicken without implanted data loggers $(N=3)$, the highest dose of LPS $(1 \mathrm{mg} / \mathrm{kg})$ was injected and blood samples were collected from the jugular vein immediately prior to and at distinct time intervals after 
$(0.5,1,2,4,8$, and $24 \mathrm{~h})$ the injection for measurement of circulating IL-6 in the plasma of these samples.

\section{Preparation and cultivation of primary cultures from the chicken hypothalamus}

The primary culture of the hypothalamus was established from topographically excised brain tissue of 1-day-old chicken. Three animals per preparation were quickly decapitated with sharp scissors and the heads were immersed shortly (10 s) in cold 70\% ethanol. Each brain was immediately removed from the skull under aseptic conditions. The cerebellum and the hypophysis were removed from the brain and a 2-mm-thick coronal brain section at the level of the hypophysis was cut with a scalpel blade. The slices were rapidly transferred to a chamber containing ice-cold oxygenated Gey's Balanced Salt Solution with 0.5\% D-glucose (both from Sigma-Aldrich), and the hypothalamic region was dissected from the coronal brain section under stereomicroscopic control (SMZ-U; Nikon, Düsseldorf, Germany). After enzymatic digestion with dispase I ( $5 \mathrm{mg} / \mathrm{ml}$; Roche Diagnostics, Mannheim, Germany) and collagenase $(2,5 \mathrm{mg} /$ $\mathrm{ml}$; Biochrom, Berlin, Germany) as well as trituration of tissue, the hypothalamus-derived cells were suspended in Dulbecco's Modified Eagle Medium (DMEM) supplemented with $10 \%$ fetal calf serum at a density of 50,000 cells $/ \mathrm{ml}$ in a humidified atmosphere of $5 \% \mathrm{CO}_{2} / 95 \%$ air at $39{ }^{\circ} \mathrm{C}$ [for details, see: Cao and Zhang 2007]. Aliquots $(350 \mu \mathrm{l})$ of the cellular suspension were plated on poly-L-lysine coated coverslips (CELL-VU Grid DRM800; Millenium Science, New York, NY, USA), which formed the bottom of a flexiPerm micro chamber (Greiner-Bio, Frickenhausen, Germany). After $2 \mathrm{~h}$, the DMEM medium was replaced by serum-free Neurobasal A medium supplemented with B27 (Invitrogen, Karlsruhe, Germany), penicillin/streptomycin $(100 \mu \mathrm{g} / \mathrm{ml})$, and L-glutamine $(2 \mathrm{mM}$ ) (both from Biochrom). During the cultivation period of 3-4 days, Neurobasal A medium was exchanged every second day. The cells were used for intracellular $\mathrm{Ca}^{2+}$ measurements and immunocytochemical characterization. Determination of IL-6 was carried out in supernatants of primary cultures of the chicken hypothalamus using a specific bioassay (Prohl et al. 2017).

\section{Measurement of intracellular calcium in single fura-2-loaded hypothalamic cells}

After 3-4 days of cultivation in Neurobasal A medium, the chicken hypothalamic cells were loaded with $2 \mu \mathrm{M}$ fura2-AM (Life Technologies, Darmstadt, Germany) in complete medium for $45 \mathrm{~min}$ in a humidified atmosphere of $5 \% \mathrm{CO}_{2} / 95 \%$ air at $37{ }^{\circ} \mathrm{C}$. For the continuous recordings of intracellular $\mathrm{Ca}^{2+}$ concentration $\left(\left[\mathrm{Ca}^{2+}\right]_{\mathrm{i}}\right)$, CELL-VU Grid coverslips were placed under an inverted microscope
(IMT-2; Olympus, Hamburg, Germany) with high-resolution camera system (Spot pursuit 23.0; Visitron Systems, Puchheim, Germany) in a specially constructed Teflon ${ }^{\circledR}$ culture chamber and superfused at a flow rate of $2.0 \mathrm{ml} / \mathrm{min}$ with $\mathrm{Ca}^{2+}$-imaging buffer ( $\mathrm{pH} 7.4,5 \mathrm{mM}$ HEPES, $130 \mathrm{mM} \mathrm{NaCl}$, $5 \mathrm{mM} \mathrm{KCl}, 1.0 \mathrm{mM} \mathrm{MgCl}_{2}, 1.25 \mathrm{mM} \mathrm{CaCl}_{2}$, and $10 \mathrm{mM}$ D-glucose; all from Sigma-Aldrich). Fluorescence measurements were performed using a filterwheel-based excitation system and analyzed with MetaFluor 7.7.8.0 software (Visitron Systems). After defining regions of interest for single cells, the time course of emitted fluorescence $(>515 \mathrm{~nm}$ ) after alternating excitations at 340 and $380 \mathrm{~nm}$, respectively, was recorded. The $340 / 380 \mathrm{~nm}$ ratios proportional to $\left[\mathrm{Ca}^{2+}\right]_{\mathrm{i}}$ were computed and analyzed. Measurements of $\left[\mathrm{Ca}^{2+}\right]_{i}$ were performed at a chamber temperature of $37^{\circ} \mathrm{C}$. Glutamate (10 $\mu \mathrm{M}$; Sigma-Aldrich), LPS (10 $\mu \mathrm{g} / \mathrm{ml}$; Sigma-Aldrich) or recombinant chicken IL-6 $(50 \mathrm{ng} / \mathrm{ml})$ (see: Schneider et al. 2001) was applied to the recording chamber via superfusion for $3 \mathrm{~min}$. At the end of the experiments, cells were exposed to high potassium $\mathrm{Ca}^{2+}$-imaging buffer consisting of $1.5 \mathrm{mM}$ HEPES, $43 \mathrm{mM} \mathrm{NaCl}, 50 \mathrm{mM} \mathrm{KCl}, 1.5 \mathrm{mM} \mathrm{MgCl}_{2}, 1.0 \mathrm{mM}$ $\mathrm{CaCl}_{2}$, and $10 \mathrm{mM} \mathrm{D}$-glucose (all from Sigma-Aldrich), serving as a vitality test especially for neurons (for further details, see: Simm et al. 2016; Pollatzek et al., 2016; Leisengang et al. 2018a; b).

\section{Immunocytochemical characterization of chicken hypothalamic primary cultures}

These experiments were performed to identify populations of cellular phenotypes, which are present in the primary culture of the chicken hypothalamus after 3-4 days of cultivation. In addition, each single neuron and astrocyte analyzed with calcium imaging was subsequently identified according to its exact position on the Cell-VU gridded glass coverslips (Ott et al. 2010; Simm et al. 2016). Phenotypic identification of chicken hypothalamic cells was carried out by immunolabeling with the following antibodies directed against cell-specific marker proteins. Glial fibrillary acidic protein (GFAP) was identified with polyclonal rabbit anti-GFAP antiserum (dilution 1:1,000; DAKO GmbH, Hamburg, Germany), whereas neurons were labeled with a monoclonal mouse antibody directed against microtubuleassociated protein $2 \mathrm{a}+\mathrm{b}($ MAP2 $\mathrm{a}+\mathrm{b} ; 1: 1,000)$ (SigmaAldrich). According to a previous study using chicken brain sections (Viertlboeck et al. 2013), microglial cells were stained with a monoclonal mouse anti-chicken KUL01 antibody (marker for macrophages, monocytes, and microglial cells) (1:1,000; Southern Biotechnologies, Birmingham, AL, USA). After the labeling procedure with the primary antibodies (Ott et al. 2010; Simm et al. 2016), cells were incubated with fluorophore-coupled secondary antisera at 1:500 or 1:1,000 dilutions in blocking buffer for $2 \mathrm{~h}$ at room 
temperature [Alexa-488 donkey anti-rabbit IgG, Alexa-488 donkey anti-mouse IgG (both from Life Technologies), Cy3 goat anti-mouse $\mathrm{IgG}$, and $\mathrm{Cy} 3$ donkey anti-rabbit IgG (both from Dianova $\mathrm{GmbH}$, Hamburg, Germany)]. After washing three times in PBS-T for 5 min each, the coverslips were embedded using a glycerol/PBS solution (Citifluor Ltd., London, UK). Cellular nuclei were labeled by incubation with 2-(4-amidinophenyl)-1H-indole-6-carboxyamidine (DAPI; Mobitec GmbH, Göttingen, Germany) for $8 \mathrm{~min}$. The cells were examined and photographed with an Olympus BX50 epifluorescence microscope (Olympus $\mathrm{GmbH}$ ) equipped with the appropriate filter systems.

\section{LPS stimulation of chicken hypothalamus primary cultures and IL- 6 measurement}

After 3-4 days of cultivation, the chicken hypothalamic cells were incubated for $2 \mathrm{~h}$ with lipopolysaccharide (LPS; 10 or $100 \mu \mathrm{g} / \mathrm{ml}$, Sigma-Aldrich) or an equivalent volume of PBS (0.1 M PBS; 0.1 M NaCl, pH 7.4; Capricorn Scientific GmbH, Ebsdorfergrund, Germany). The LPS stock solution was dissolved in PBS at concentrations of $1.0 \mathrm{mg} / \mathrm{ml}$ and stored at $-20{ }^{\circ} \mathrm{C}$. After incubation, the supernatants were removed from the cells and stored at $-20^{\circ} \mathrm{C}$ for later measurement of IL-6. The LPS doses to stimulate neuro-glial primary cultures of chicken were chosen according to own previous studies (Ott et al. 2010; Simm et al. 2016; Leisengang et al. 2018b) and to pilot experiments.

IL-6 was measured in supernatants of chicken hypothalamic primary cultures and in plasma of LPS-injected chicken (see above) by an assay based on the dose-dependent growth stimulation of IL-6 on the 7TD1 hybridoma cell line as previously described (Prohl et al. 2017). The assay was conducted in sterile 96-well microtiter plates. In each well, $50007 \mathrm{TD} 1$ cells were incubated for $72 \mathrm{~h}$ with serial dilutions of the supernatants or with different concentrations of a human IL-6 standard (code 89/548; National Institute for Biological Standards and Control, South Mimms, U.K.). The number of living cells after $72 \mathrm{~h}$ was determined using the dimethylthiazol-diphenyl tetrazolium bromide (MTT) colorimetric assay. This assay has been used previously to measure bioactive IL-6 in chicken (Nakamura et al. 1998; De Boever et al. 2008, 2009).

\section{Data evaluation and statistics}

The mean $T_{\mathrm{b}}$ rhythms of chicken ( $N=3$ per group) injected i.v. with PBS, a low dose $(0.1 \mu \mathrm{g} / \mathrm{kg})$, or a high dose $(1 \mathrm{mg} /$ $\mathrm{kg}$ ) of LPS are presented from 2 days before until 4 days after the respective injection. In addition, the mean day-time temperature for each chicken was calculated from $7 \mathrm{~h}$ until $20 \mathrm{~h}$; the respective night-time temperature from $23 \mathrm{~h}$ until
$5 \mathrm{~h}$. These periods were chosen to omit the periods of $T_{\mathrm{b}}$ decrease to its night-time nadir and the increase of $T_{\mathrm{b}}$ to its day-time peak (see Fig. 1a). Day- and night-time $T_{\mathrm{b}}$ values were compared by the non-parametric Kruskal-Wallis test with Dunn's post hoc analysis.

For the $\mathrm{Ca}^{2+}$-imaging experiments, the numbers of cells of a given phenotype, responsive to a defined stimulus, were calculated as a percentage (\%) of all cells of this phenotype investigated. Stimulus-induced $\mathrm{Ca}^{2+}$-transients were expressed as the difference between resting baseline $\left[\mathrm{Ca}^{2+}\right]_{\mathrm{i}}$ measured prior to the respective stimulation and the stimulus-induced $\left[\mathrm{Ca}^{2+}\right]_{\mathrm{i}}$ peak $(\Delta$ ratio $[340 / 380 \mathrm{~nm}])$. A difference in $\Delta$ ratio $[340 / 380 \mathrm{~nm}]$ values of more than 0.05 was considered to be a stimulus-induced $\mathrm{Ca}^{2+}$ signal. This procedure can be taken as a strict exclusion criterion. Concentrations of IL- 6 were measured in supernatants of chicken hypothalamic primary culture wells, derived from five distinct preparations ( $N=28$ per group), which were stimulated with PBS (controls) or LPS $(10 \mu \mathrm{g} / \mathrm{ml}$ and $100 \mu \mathrm{g} / \mathrm{ml}$, respectively). Data are presented as means \pm standard error of the mean (SEM) and compared by an analysis of variance (ANOVA) followed by the Newman-Keuls multiple comparisons test. The calculations were carried out using the software package GraphPad Prism 5 (GraphPad Software Inc., La Jolla, CA, USA).

\section{Results}

\section{Dose-dependent influence of LPS on $T_{b}$ rhythms of chicken}

All investigated chicken showed a pronounced circadian rhythm of $T_{\mathrm{b}}$ with more than $1{ }^{\circ} \mathrm{C}$ lower night-time temperature (Figs. 1, 2).

This rhythm was not disturbed by i.v. injections of PBS $(N=3$; Figs. 1a, 2a). Injections of a low LPS dose $(0.1 \mu \mathrm{g} /$ $\mathrm{kg} ; N=3$ ) caused a fever, which started with a latency of $2 \mathrm{~h}$, reached a peak at midnight (6 $\mathrm{h}$ after LPS injection), and lasted for the entire night-time period (Fig. 1b, b*). The mean night-time temperatures following LPS injection was significantly elevated $(p<0.001$; Kruskal-Wallis test with Dunn's post hoc analysis) as compared to $T_{\mathrm{b}}$ values measured the night before and the night after administration of LPS (Fig. 2b*). During the following days, chicken treated with the low LPS dose again showed their normal circadian rhythm of $T_{\mathrm{b}}$. The fever pattern after administration of a high LPS dose $(1 \mathrm{mg} / \mathrm{kg}, N=3)$ was completely different. During the night after LPS injection, chicken developed no fever, but rather a tendency for a hypothermic response, followed by a normal return to day-time $T_{\mathrm{b}}$. The usual decline of $T_{\mathrm{b}}$ during the following night, however, was omitted, so 

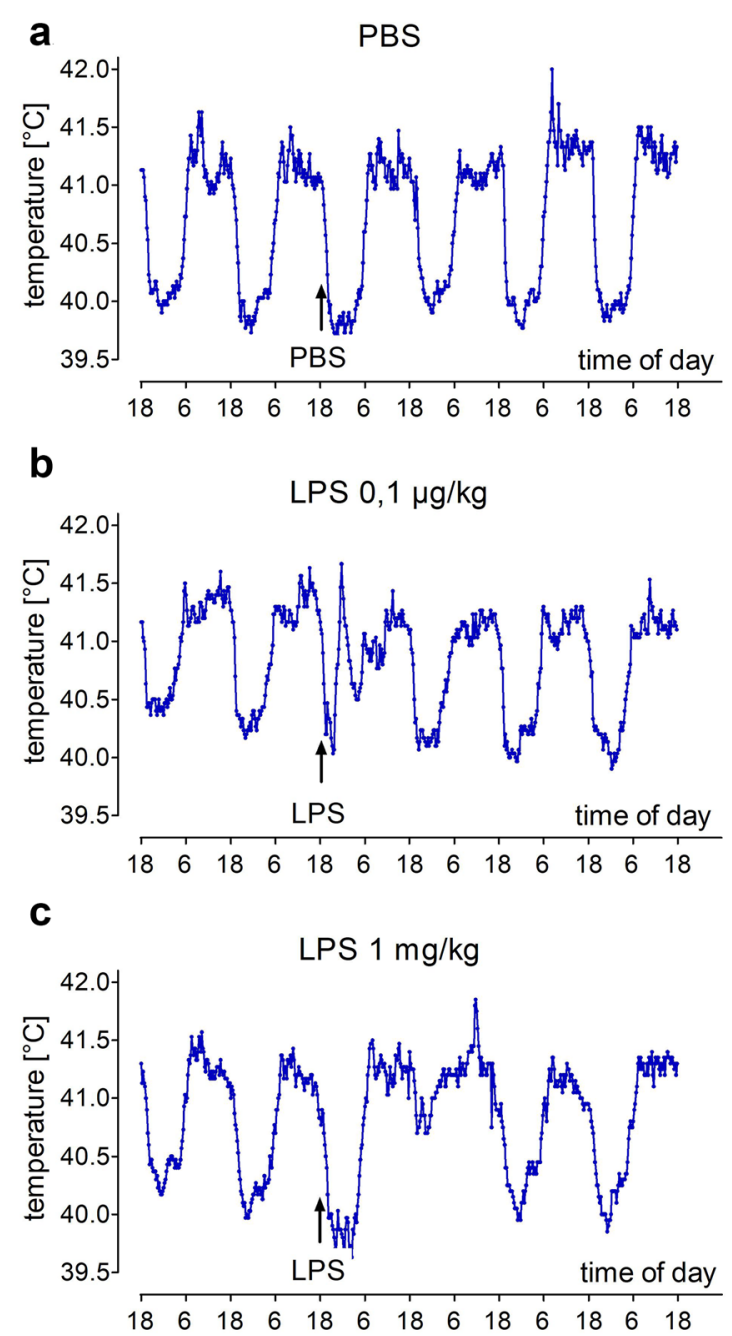

Fig. $1 T_{\mathrm{b}}$ rhythms and LPS fever in chicken. Mean $T_{\mathrm{b}}$ in three groups of chicken ( $N=3$ per group), recorded via data loggers from 2 days before until 4 days after i.v. injections at $18 \mathrm{~h}$ of PBS (a), $0.1 \mu \mathrm{g} / \mathrm{kg}$

that the circadian rhythm of $\mathrm{Tb}$ was disrupted. Thereafter, chicken re-established their normal $T_{\mathrm{b}}$ rhythm (Fig. 1c, $\mathrm{c}^{*}$ ). A significant increase of $T_{\mathrm{b}}$ was thus observed with a delay of one night $(p<0.001$; Kruskal-Wallis test with Dunn's post hoc analysis Fig. 2c).

In a separate group of chicken $(N=3)$, the IL-6 response to the high LPS dose was determined. Compared to circulating levels of IL-6 measured prior to the injection of LPS, bioactive IL-6 was strongly elevated for at least $8 \mathrm{~h}$ with peak values between $1-4 \mathrm{~h}$ after LPS injection. After $24 \mathrm{~h}$, IL-6 in plasma almost returned to baseline values (Fig. 3).

\section{Influence of LPS and chicken IL-6 on a neuro-glial culture of chicken hypothalamus}

After determination of the best conditions for a neuro-glial primary culture of the chicken hypothalamus, the cellular
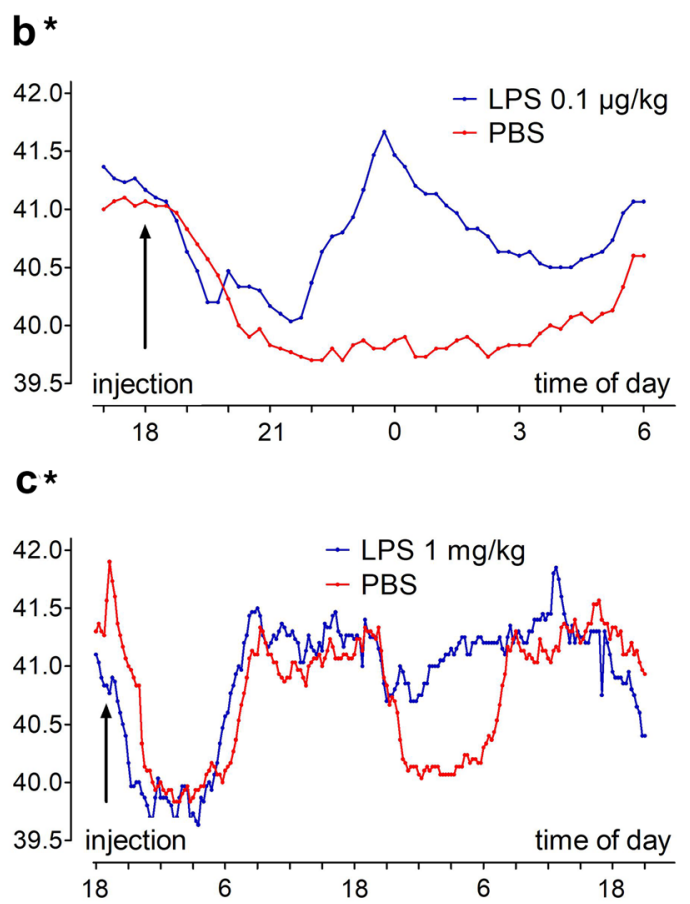

LPS (b), or $1 \mathrm{mg} / \mathrm{kg}$ LPS (c). $\mathbf{b}^{*}, \mathbf{c}^{*}$ Higher resolution of the febrile periods of chicken injected i.v. with $0.1 \mu \mathrm{g} / \mathrm{kg}$ LPS $\left(\mathbf{b}^{*}\right)$ or $1 \mathrm{mg} / \mathrm{kg}$ LPS $\left(\mathbf{c}^{*}\right)$

phenotypes present in the culture system were characterized by double labeling immunocytochemistry, employing cell-type-specific antibodies. Each cell culture well used for in vitro experiments contained $614 \pm 72$ neurons, $1354 \pm 129$ astrocytes, and $582 \pm 27$ microglial cells on average $(N=7)$ (Fig. 4).

Astrocytes, neurons, and microglial cells represented about $75 \%$ of all cells present in one well of the primary culture.

Employing the $\mathrm{Ca}^{2+}$-imaging technique in combination with post-experimental immunocytochemistry, the numbers and percentages of cells directly activated by glutamate, LPS, or chicken IL- 6 could be determined. In response to superfusion of primary cultures with $10 \mu \mathrm{M}$ glutamate (GLUT), the most important excitatory transmitter within the hypothalamus, for $3 \mathrm{~min}$ at $37^{\circ} \mathrm{C}, 176$ out of $337 \mathrm{neu}-$ rons $(52.2 \%)$ and 21 out of 234 astrocytes $(9 \%)$ responded 

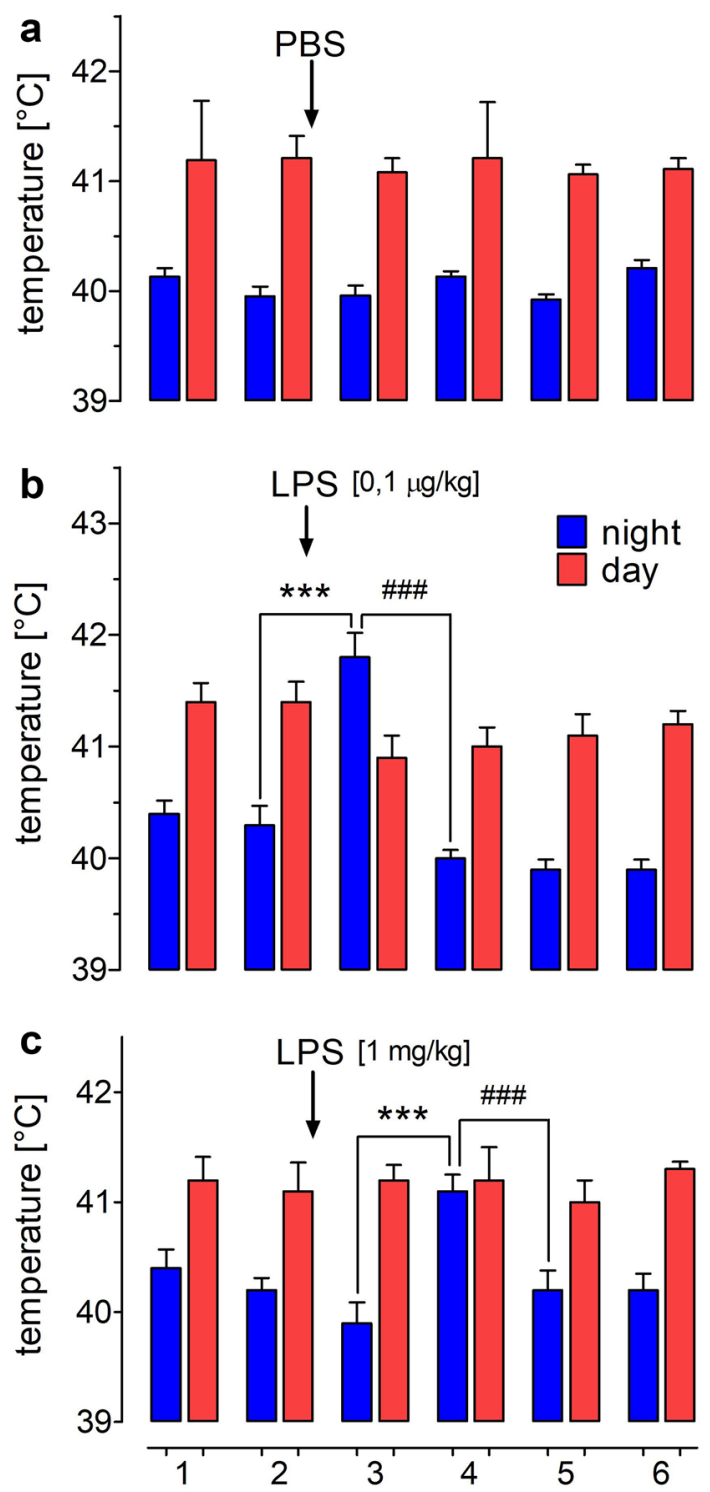

Fig. 2 Evaluation of $T_{\mathrm{b}}$ rhythms during LPS fever in chicken. Mean day-time temperatures of chicken (red) [calculated from 7 until $20 \mathrm{~h}$ ] and the respective night-time temperatures (blue) [calculated from 23 until 5 h]. Chicken were injected i.v. with PBS (a), $0.1 \mu \mathrm{g} / \mathrm{kg}$ LPS (b), or $1 \mathrm{mg} / \mathrm{kg}$ LPS (c) ( $N=3$ per group). These periods were chosen to omit the periods of decrease of $T_{\mathrm{b}}$ to its night-time nadir and the increase of $T_{\mathrm{b}}$ to its day-time peak (see Fig. 1a). Chicken treated i.v. with $0.1 \mu \mathrm{g} / \mathrm{kg}$ LPS developed fever during the night following the injection (b); the i.v. injection of $1 \mathrm{mg} / \mathrm{kg}$ LPS caused fever during the second night following the injection (c). [***; ${ }^{\# \# \#: ~} p<0.001$; KruskalWallis test with Dunn's post hoc analysis] (color figure online)

with a pronounced and transient increase of intracellular $\mathrm{Ca}^{2+}$ concentration. Representative examples for these responses are shown in Fig. 5.

In the next experiments, the effects of superfusion of primary cell culture wells with $10 \mu \mathrm{g} / \mathrm{ml}$ LPS or $50 \mathrm{ng} / \mathrm{ml}$

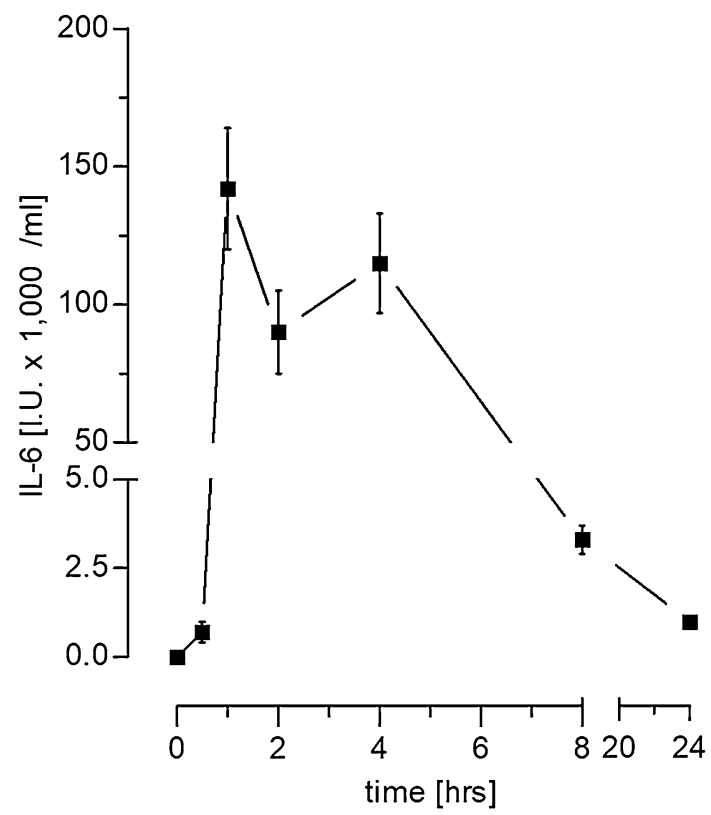

Fig. 3 Bioactive IL-6 in serum of LPS-injected chicken. In a group of chicken $(N=3)$, the highest dose of LPS $(1 \mathrm{mg} / \mathrm{kg})$ was injected and blood samples were collected from the jugular vein immediately prior to and at distinct time intervals after $(0.5,1,2,4,8$, and $24 \mathrm{~h})$ the LPS injection for measurement of circulating IL- 6 in the plasma of these samples. The highest concentrations of IL- 6 were determined between 1 and $4 \mathrm{~h}$ after LPS was injected

chicken IL- 6 on $\left[\mathrm{Ca}^{2+}\right]_{\mathrm{i}}$ of Fura-2-loaded chicken hypothalamic cells were investigated. (Fig. 6).

Quantitative analysis of these experiments revealed that 13 out of 337 investigated neurons (4\%) and 28 out of 234 astrocytes (12\%) responded to LPS with a pronounced and transient increase of $\left[\mathrm{Ca}^{2+}\right]_{\mathrm{i}}$ (Fig. 6a). Even higher percentages of hypothalamic cells responded to superfusion with chicken IL-6 (Fig. 6b). IL-6-induced intracellular $\mathrm{Ca}^{2+}$ signals were recorded in 18 out of 158 neurons (11.5\%) and in 56 out of 252 astrocytes (22\%).

In a final experiment, the capacity of chicken hypothalamic primary cultures to produce and release IL-6 upon stimulation with LPS compared to PBS was tested (Fig. 7, $N=28$ in each group).

Incubation of cells in the presence of 10 or $100 \mu \mathrm{g} / \mathrm{ml}$ LPS for $2 \mathrm{~h}$ caused a significant increase of bioactive IL-6 in the supernatants of hypothalamic cultures $(p<0.001$; ANOVA followed by Newman-Keuls test) in a dose-dependent manner. In the presence of $10 \mu \mathrm{g} / \mathrm{ml}$ LPS, there was a fourfold increase of IL- 6 in the supernatants $(243 \pm 45$ I.U./ $\mathrm{ml})$ compared to controls $(61 \pm 6 \mathrm{I} . \mathrm{U} . / \mathrm{ml})$. Stimulation with $100 \mu \mathrm{g} / \mathrm{ml}$ LPS even evoked an eightfold elevation of bioactive IL-6 in the supernatants (492 \pm 91 I.U./ml). 
Fig. 4 Cellular phenotypes present in neuro-glial primary cultures of the chicken hypothalamus. Immunolabeling with primary antibodies directed against GFAP for astrocytes (a), MAP $2 a+b$ for neurons $(\mathbf{b})$, and KUL-01 for microglial cells (c). Secondary antibodies employed were coupled to fluorophors such as Alexa488 (green) or Cy3 (red). Cellular nuclei were stained with DAPI (blue). Bars represent $6 \mu \mathrm{m}$ (color figure online)
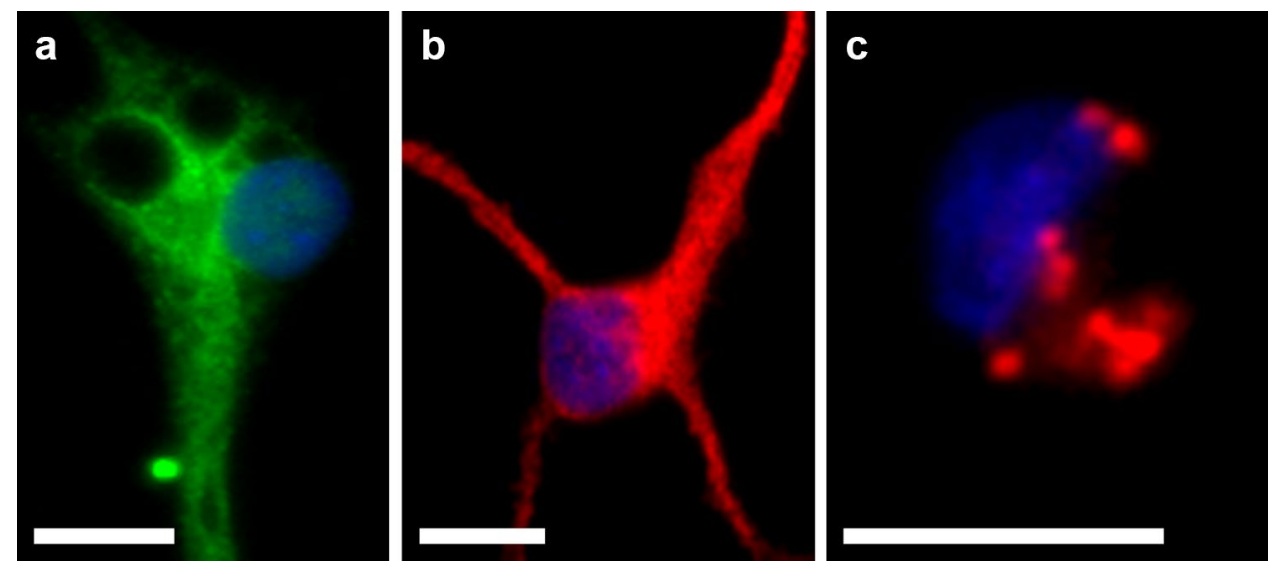

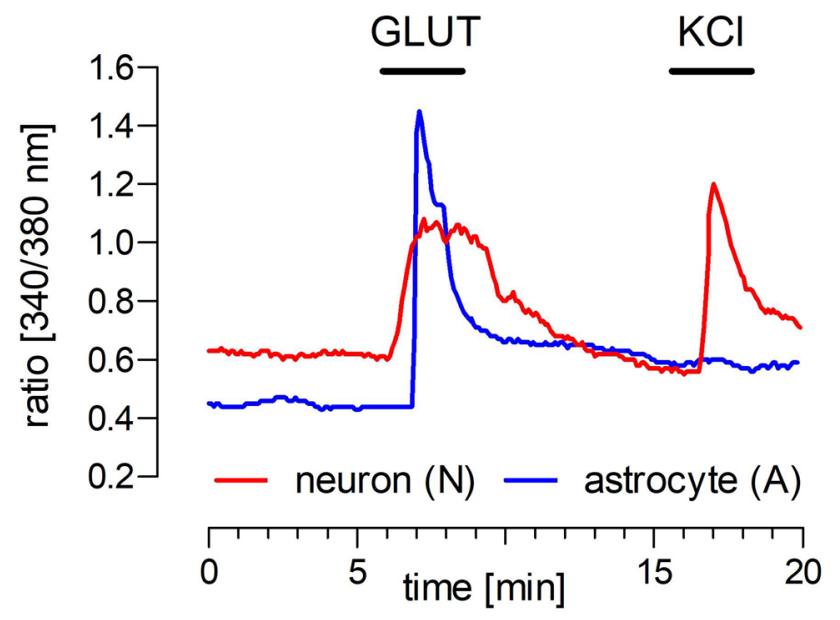

Fig. 5 Neurons and astrocytes of chicken hypothalamic primary cultures respond to glutamate with an increase of $\left[\mathrm{Ca}^{2+}\right]_{\mathrm{i}}$. Examples of intracellular calcium signals recorded from one neuron and one astrocyte in a primary culture derived from the chicken hypothalamus. Both cells responded to superfusion with $10-\mu \mathrm{M}$ glutamate. The neuron also responded to buffer containing a high concentration of $\mathrm{KCl}$ $(50 \mathrm{mM})$ with a pronounced increase of $\left[\mathrm{Ca}^{2+}\right]_{\mathrm{i}}$, whereas the $\mathrm{KCl}$ response is missing in the astrocyte

\section{Discussion}

\section{Fever in birds}

In the present experiments, chicken were injected at the beginning of the night-time, when $T_{\mathrm{b}}$ moved to its nadir, with various doses of LPS and recorded $T_{\mathrm{b}}$ for several days (Figs. 1 and 2). A low dose of LPS $(0.1 \mu \mathrm{g} / \mathrm{kg})$, which would hardly give rise to detectable fever when injected in the active phase (Maloney and Gray 1998), resulted in monophasic fevers of more than $6 \mathrm{~h}$ duration in our experiments. Even the very low dose of $10 \mathrm{ng} / \mathrm{kg}$ LPS caused a fever of shorter duration in chicken (not shown). This means that chicken are rather sensitive to LPS, in contrast to rats or mice, at least when the pyrogen is injected prior to or during night-time. These and other mammalian species have to be challenged with much higher LPS doses to evoke a fever (Kluger 1991; Romanovsky et al. 2005; Rudaya et al. 2005). The pattern of fever induced by a high dose of LPS in chicken proved to be even more interesting (Figs. 1c, $2 c)$. During the night of injection, there was no fever at all, but just a slight tendency for the induction of a hypothermic response. Fever occurred with a delay of $24 \mathrm{~h}$ and the normal decrease of $T_{\mathrm{b}}$ during the night was omitted in chicken treated with the high dose of LPS. Such a delayed fever response after challenge with high doses of LPS is also observed in mammalian species, but it is preceded by pronounced hypothermia (Kozak et al. 1998; Töllner et al. 2000; Leon, 2004). Even in those few studies, in which $T_{\mathrm{b}}$ of birds injected with a high LPS dose was measured, the small hypothermic responses never exceeded the range of the normal circadian $T_{\mathrm{b}}$ rhythms of the investigated avian species (De Boever et al. 2009; Sköld-Chiriac et al. 2015; Fig. 1 of this study). The reason for this discrepancy to the mammalian thermal response to LPS may be due to differences within the responsible endogenous cytokine network of birds (Staeheli et al. 2001).

\section{The role of IL- 6 and other cytokines in avian fever}

In a small group of chicken $(N=3)$, circulating IL-6 was measured in response to LPS injections (Fig. 3). The increase of IL-6 in the blood to its peak seems to occur faster (within $1 \mathrm{~h}$ ) compared to several mammalian species (Jansky et al. 1995; Harré et al. 2002). In these species, guinea pigs, and rats, the LPS-induced peak of circulating IL-6 is reached with some delay and is preceded the appearance of TNF- $\alpha$ in the blood. From the cytokines, which are released within the initial phase of mammalian fever, TNF- $\alpha$ has been identified as the candidate to be involved in the manifestation of the hypothermic component of the thermal response to high LPS doses (Töllner et al. 2000; Leon 2004; 

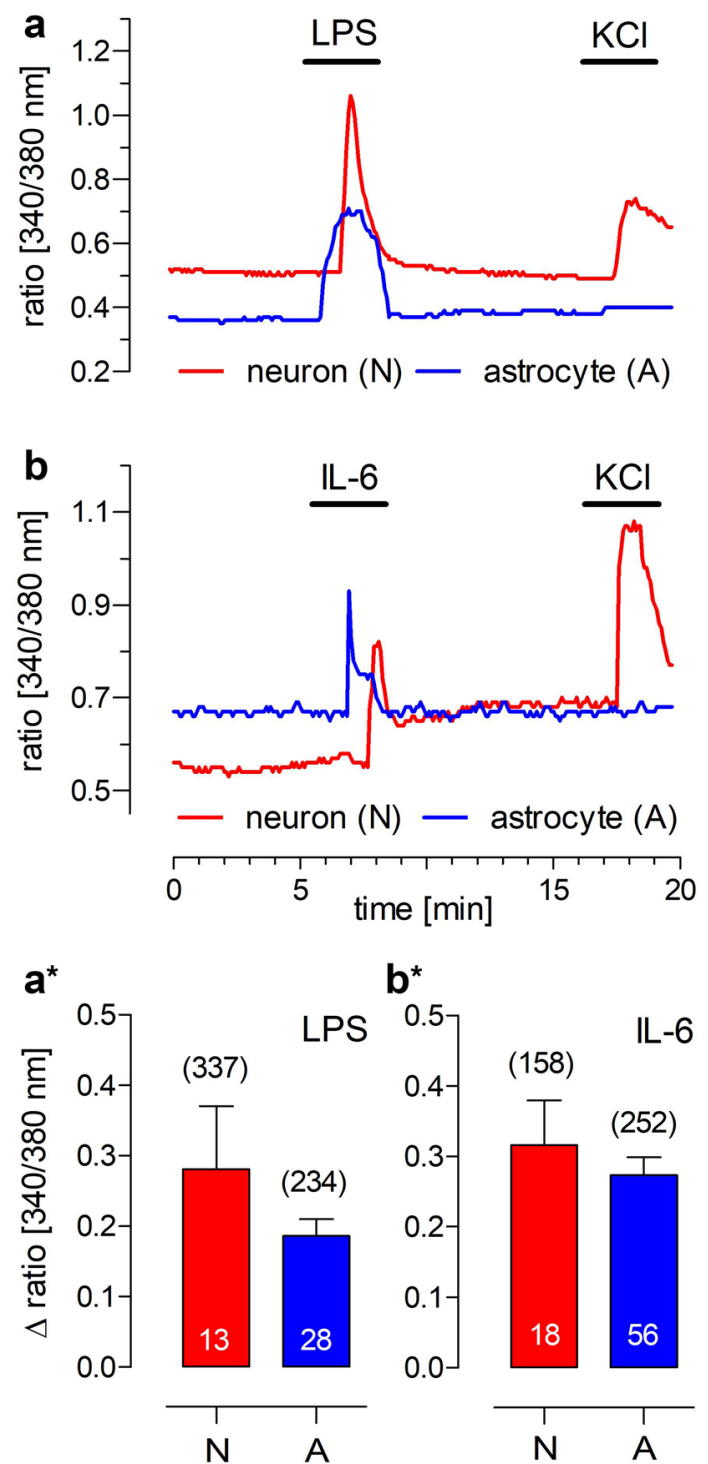

Fig. 6 Intracellular calcium signals of hypothalamic neurons $(\mathrm{N})$ and astrocytes (A) upon superfusion with LPS or chicken IL-6. Examples of intracellular calcium signals recorded from one neuron and one astrocyte each of a primary neuro-glial culture well derived from the chicken hypothalamus in response to superfusion with $10 \mu \mathrm{g} / \mathrm{ml} \mathrm{LPS}$ (a) or $50 \mathrm{ng} / \mathrm{ml}$ chicken IL-6 (b). Evaluation of the $\mathrm{Ca}^{2+}$ signals of all investigated cells, with $\Delta$ ratio $[340 / 380 \mathrm{~nm}]$ fluorescence values as measure of the intracellular-free calcium concentration. Columns in $\mathbf{a}^{*}$ and $\mathbf{b}^{*}$ represent means \pm S.E.M. of those neurons $(\mathrm{N})$ or astrocytes (A), which showed an LPS-induced (a) or an IL-6-induced (b) increase of $\left[\mathrm{Ca}^{2+}\right]_{\mathrm{i}}$. Numbers of investigated cells are indicated in parentheses above the columns; numbers of responsive cells are shown within the columns

Garami et al. 2019). Interestingly, of these proinflammatory cytokines TNF- $\alpha$ was supposed to be absent in the avian genome (Staeheli et al. 2001) until it was recently identified and characterized in chicken (Rohde et al. 2018). The lack of pronounced hypothermia in birds under these conditions might be due to the lack of a significant contribution

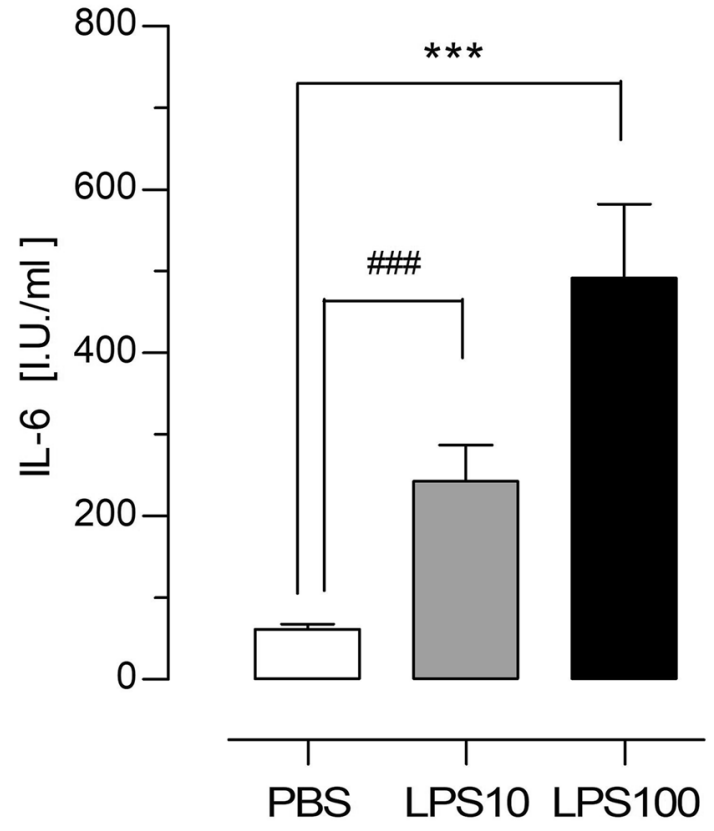

Fig. 7 Release of IL-6 into supernatants of chicken hypothalamus primary cultures. LPS-induced release of IL-6 into supernatants of chicken hypothalamic cell cultures stimulated with $10 \mu \mathrm{g} / \mathrm{ml}$ LPS (LPS 10) or $100 \mu \mathrm{g} / \mathrm{ml}$ LPS (LPS 100) compared to stimulations with PBS ( $N=28$ wells from five distinct preparations in each group). Data represent mean values with S.E.M. [***; ${ }^{* \# \#}: p<0.001$; ANOVA followed by the Newman-Keuls multiple comparison test]

of TNF- $\alpha$ to the thermal response to LPS in birds. Whether there is a significant contribution of this recently discovered avian cytokine (Rohde et al. 2018) in LPS fever in birds at all will have to be determined. For other cytokines with pyrogenic properties, i.e., IL-1 $\beta$ and IL- 6 , there is more evidence for a significant role in fever in birds (Marais et al. 2011; Gray et al. 2013). Namely, IL-6 can be measured in increased amounts in the circulation of LPS-stimulated birds (Nakamura et al. 1998; De Boever et al. 2008, 2009; Adelman et al. 2010; own measurements). However, peripherally released or administered IL-6 has only weak pyrogenic capacities in mammals (Cartmell et al. 2000; Harré et al. 2002; Rummel et al. 2006). IL-6 is rather considered to be an endogenous pyrogen acting centrally within the anterior hypothalamus (Klir et al. 1993; Lenczowski et al. 1999). Indeed, in the only experimental study on the role of IL-6 in the avian febrile response, this cytokine was administered into the third ventricle of the brain close to the hypothalamus and caused dose-dependent fevers (Marais et al. 2011). In the same study, it was shown that central injections of antibodies against chicken IL- 6 suppressed fever. The authors concluded that brain-intrinsic IL-6 serves as terminal mediator of avian fever (Marais et al. 2011; Gray et al. 2013). 


\section{Inflammatory activation of cells from chicken hypothalamus}

To investigate the responses of the chicken hypothalamus to exogenous (LPS) or endogenous (IL-6) pyrogens at the cellular level, a neuro-glial primary culture of chicken hypothalamic tissue was established for the first time (Fig. 4). The cellular phenotypes of about $75 \%$ of all cells in this culture could be identified as neurons, astrocytes, and microglial cells (Fig. 4). According to previous corresponding investigations in mammalian hypothalamic primary cultures (Simm et al. 2016), presumably oligodendrocytes represent the predominant part of those cells, for which the cellular phenotype could not be determined due to the lack of an appropriate antibody specific for avian oligodendrocytes.

The central goal was to investigate whether a direct activation of hypothalamic cells by inflammatory stimuli could be demonstrated. Special focus was directed to IL-6, one of the putative centrally acting terminal mediators of avian fever. More than $50 \%$ of all tested neurons and $9 \%$ of astrocytes cultured from the chicken hypothalamus responded to the excitatory transmitter glutamate with a pronounced increase of $\left[\mathrm{Ca}^{2+}\right]_{\mathrm{i}}$ (Fig. 5). Although these percentages are higher in cultures obtained from the rat hypothalamus (Simm et al. 2016; Leisengang et al. 2018a), it is obvious that glutamate represents a very important excitatory transmitter not only in the mammalian but also in the avian hypothalamus. More interesting in the context of this study was the observation that $11.5 \%$ of all neurons and even $22 \%$ of all astrocytes in the primary culture were directly activated by chicken IL-6 (Fig. 5). Electrophysiological studies showed that IL-6 can induce neuronal responses in hypothalamic tissue slices, which are compatible with the generation of fever (Xin and Blatteis 1992). A direct link between the IL-6 induced $\mathrm{Ca}^{2+}$-signals in hypothalamic cells (Fig. 6) and the suggested contribution of hypothalamic IL-6 to the febrile response of chicken is difficult to draw. Still, the present experiments clearly show that hypothalamic neurons and astrocytes directly respond to this cytokine. This is remarkable in so far, as the hypothalamus is not only a target, but also a site of production for this cytokine (Fig. 7). Under in vivo conditions, a localized production of IL- 6 within the hypothalamus and a subsequent influence on hypothalamic neurons might be a key event in the manifestation of the avian febrile response. The fever data show that the febrile response of chicken to LPS occurred with delay of at least some hours (Figs. 1 and 2). During this period, the intrahypothalamic production of IL-6 might have been initiated. One possibility for a process like this could be the entrance of LPS into or around hypothalamic tissue under conditions of systemic inflammation. Some neurons and even more astrocytes could be detected, which were directly activated by LPS (Fig. 6a) and showed a pronounced increase of
$\left[\mathrm{Ca}^{2+}\right]_{\mathrm{i}}$. Some authors suggested a possible mechanism for the interplay among LPS-induced activation of its cognate receptor TLR4 (Toll-like receptor 4), a subsequent rise in intracellular $\mathrm{Ca}^{2+}$, and an increased production of cytokines such as IL-6 (Franco et al. 2006; Mayo et al. 2008). Whether or not a mechanism like this operates within LPS-stimulated neuro-glial primary cultures of the chicken hypothalamus will have to be determined.

In conclusion, our experiments and measurements provide further evidence that IL- 6 is an important endogenous pyrogen not only in mammals, but also in birds, and that the anterior hypothalamus is a putative site of action for this cytokine in both classes of homeothermic vertebrates. Future experiments could employ more refined primary cultures from specific nuclei of the chicken hypothalamus with putative thermoregulatory functions, for example the chicken medial preoptic nucleus (Kuenzel and Tienhoven 1982). In such a refined culture, it will be possible to investigate the responses of neurons to warming (Leisengang et al 2018a) and the modulation of these responses by IL- 6 or $\mathrm{PGE}_{2}$ (Simm et al. 2016) to obtain further insight into the function of avian thermoregulatory structures.

Acknowledgements Open Access funding provided by Projekt DEAL.

Open Access This article is licensed under a Creative Commons Attribution 4.0 International License, which permits use, sharing, adaptation, distribution and reproduction in any medium or format, as long as you give appropriate credit to the original author(s) and the source, provide a link to the Creative Commons licence, and indicate if changes were made. The images or other third party material in this article are included in the article's Creative Commons licence, unless indicated otherwise in a credit line to the material. If material is not included in the article's Creative Commons licence and your intended use is not permitted by statutory regulation or exceeds the permitted use, you will need to obtain permission directly from the copyright holder. To view a copy of this licence, visit http://creativecommons.org/licenses/by/4.0/.

\section{References}

Adelman JS, Bentley GE, Wingfield JC, Martin LB, Hau M (2010) Population differences in fever and sickness behaviors in a wild passerine: a role for cytokines. J Exp Biol 213:4099-4109

Bicego KC, Barros RCH, Branco LGS (2007) Physiology of temperature regulation: comparative aspects. Comp Biochem Physiol A Mol Integr Physiol 147:616-639

Cao A, Zhang C (2007) Sex-specific effects of androgen and estrogen on proliferation of the embryonic chicken hypothalamic neurons. Endocrine 31:161-166

Cartmell T, Poole S, Turnbull AV, Rothwell NJ, Luheshi GN (2000) Circulating interleukin- 6 mediates the febrile response to localized inflammation in rats. J Physiol 526(3):653-661

Chai Z, Gatti S, Toniatti C, Poli V, Bartfai T (1996) Interleukin (IL)-6 gene expression in the central nervous system is necessary for fever response to lipopolysaccharide or IL-1b: a study on IL-6 deficient mice. J Exp Med 183:311-316 
De Boever S, Beyaert R, Vandemaele F, Baert K, Duchateau L, Goddeeris B, De Backer P, Croubels S (2008) The influence of age and repeated lipopolysaccharide administration on body temperature and the concentration of interleukin- 6 and IgM antibodies against lipopolysaccharide in broiler chickens. Avian Pathol. 37:39-44

De Boever S, Croubels S, Meyer E, Sys S, Beyaert R, Ducatelle R, De Backer P (2009) Characterization of an intravenous lipopolysaccharide inflammation model in broiler chickens. Avian Pathol. 38:403-411

Erhardt W, Henke J, Baumgartner C, Tacke S (eds) (2011) Anaesthesie und analgesie beim klein- und heimtier: mit exoten, labortieren, vögeln, reptilien, amphibien und fischen, 2nd edn. Schattauer/ Thieme, Stuttgart

Eskillson A, Mirrasekhian E, Dufour S, Schwaninger M, Engblom D, Blomqvist A (2014) Immune-induced fever is mediated by IL-6 receptors on brain endothelial cells coupled to STAT3-dependent induction of brain endothelial prostaglandin synthesis. J Neurosci 34:15957-15961

Eskillson A, Matsuwaki T, Shionoya K, Mirrasekhian E, Zajdel J, Schwaninger M, Engblom D, Blomqvist A (2017) Immuneinduced fever is dependent on local but not generalized prostaglandin E2 synthesis in the brain. J Neurosci 37:5035-5044

Franco L, Bodrato N, Moreschi I, Usai C, Buzzone S, Scarf S, Zocchi E, De Flora A (2006) Cyclic ADP-ribose is a second messenger in the lipopolysaccharide -stimulated activation of murine N9 microglial cell line. J Neurochem 99:165-176

Garami A, Steiner AA, Romanovsky AA (2019) Fever and hypothermia in systemic inflammation. Handb Clin Neurol 157:565-597

Gray DA, Marais M, Maloney SK (2013) A review of the physiology of fever in birds. J Comp Physiol B 183:297-312

Harré EM, Roth J, Pehl U, Küth M, Gerstberger R, Hübschle T (2002) Selected contribution: role of IL-6 in LPS-induced nuclear STAT3 translocation in sensory circumventricular organs during fever in rats. J Appl Physiol 92:2657-2666

Jansky L, Vybiral S, Pospisilova D, Roth J, Dornand J, Zeisberger E, Kaminkova J (1995) Production of systemic and hypothalamic cytokines during the early phase of endotoxin fever. Neuroendocrinology 62:55-61

Klir JJ, Roth J, Szelenyi Z, McClellan JL, Kluger MJ (1993) Role of hypothalamic interleukin-6 and tumor necrosis factor- $\alpha$ in LPS fever in rat. Am J Physiol Regul Integr Comp Physiol 265:R512-R517

Kluger MJ (1991) Fever: role of pyrogens and cryogens. Physiol Rev $71: 93-127$

Kozak W, Kluger MJ, Soszynsky D, Conn CA, Rudolph K, Leon LR, Zheng H (1998) IL-6 and IL-1 in fever: studies using cytokinedeficient (knockout) mice. Ann N Y Acad Sci 856:33-47

Kuenzel WJ, Van Tienhoven A (1982) Nomenclature and location of avian hypothalamic nuclei and associated circumventricular organs. J Comp Neurol 206:293-313

Leisengang S, Ott D, Gerstberger R, Rummel C, Roth J (2018a) Effects of thermal stimulation on neurons and astrocytes cultured from the rat median preoptic nucleus. NeuroReport 29:1468-1472

Leisengang S, Ott D, Murgott J, Gerstberger R, Rummel C, Roth J (2018b) Primary cultures from rat dorsal root ganglia: responses of neurons and glial cells to somatosensory or inflammatory stimulation. Neuroscience 394:1-13

Lenczowski MJP, Bluthe RM, Roth J, Rees GS, Rushforth DA, Van Dam AM, Tilders FJH, Dantzer R, Rothwell NJ, Luheshi GN (1999) Central administration of rat IL-6 induces HPA activation and fever but not sickness behavior in rats. Am J Physiol Regul Integr Comp Physiol 276:R652-R658

Leon LR (2004) Hypothermia in systemic inflammation: role of cytokines. Front Biosci 9:1877-1888

Li Z, Perlik V, Feleder C, Tang Y, Blatteis CM (2006) Kupffer cellgenerated PGE2 triggers the febrile response of guinea pigs to intravenously injected LPS. Am J Physiol Regul Integr Comp Physiol 290:R1262-R1270

Luker F, Mitchell D, Laburn H (2000) Fever and motor activity in rats following day and night injection of Staphylococcus aureus cell walls. Am J Physiol Regul Integr Comp Physiol 279:R610-R616

Maloney SK, Gray DA (1998) Characteristics of the febrile response in Pekin ducks. J Comp Physiol B 168:177-182

Marais M, Maloney SK, Gray DA (2011) Brain IL-6 and prostaglandindependent actions of IL-1 and lipopolysaccharide in avian fever. Am J Physiol Regul Integr Comp Physiol 301:R791-R800

Mayo L, Jacob-Hirsch J, Amarilio N, Rechavi G, Moutin MJ, Lund FE, Stein R (2008) Dual role of CD38 in microglial activation and activation-induced cell death. J Immunol 181:92-103

Nakamura K, Mitarai Y, Yoshioka M, Koizumi N, Shibahara T, Nakajima Y (1998) Serum levels of interleukin-6, 1-acid glycoprotein, and corticosterone in 2-week-old chickens inoculated with Escherichia coli lipopolysaccharide. Poultry Sci 77:908-911

Nomoto S (1996) Diurnal variations in fever induced by intravenous LPS injection in pigeons. Pflügers Arch Eur J Physiol 431:987-989

Ott D, Murgott J, Rafalzik S, Wuchert F, Schmalenbeck B, Roth J, Gerstberger R (2010) Neurons and glial cells of the rat organum vasculosum laminae terminalis directly respond to lipolysaccharide and pyrogenic cytokines. Brain Res 1363:93-106

Pollatzek E, Hitzel N, Ott D, Raisl K, Reuter B, Gerstberger R (2016) Functional expression of $\mathrm{P} 2$ purinoceptors in a primary neuroglial cell culture of the rat arcuate nucleus. Neuroscience 327:95-114

Prohl A, Ostermann CH, Rummel CD, Roth J, Reinhold P (2017) Circulating and broncho-alveolar interleukin- 6 in relation to body temperature in an experimental model of bovine Chlamydia psittaci infection. PLoS ONE 12:e0189321

Rohde F, Schusser B, Hron T, Farkasova H, Plachy J, Härtle S, Hejnar J, Elleder D, Kaspers B (2018) Characterization of chicken tumor necrosis factor- $\alpha$, a long missed cytokine in birds. Front Immunol 9:605

Romanovsky AA, Almeida MC, Aronoff DM, Ivanov AJ, Konsman JP, Steiner AA, Turek VF (2005) Fever and hypothermia in systemic inflammation: recent discoveries and revisions. Front Biosci 10:2193-2216

Roth J, Blatteis CM (2014) Mechanisms of fever production and lysis: lessons from experimental LPS fever. Compr Physiol 4:1563-1604

Rudaya AY, Steiner AA, Robbins JR, Dragic AS, Romanovsky AA (2005) Thermoregulatory response to lipopolysaccharide in the mouse: dependence on route and ambient temperature. Am J Physiol Regul Integr Comp Physiol 289:R1244-R1252

Rummel C, Voss T, Matsumura K, Korte S, Gerstberger R, Roth J, Hübschle T (2005) Nuclear STAT3 translocation in guinea pig and rat brain endothelium during systemic challenge with lipopolysaccharide and interleukin-6. J Comp Neurol 491:1-14

Rummel C, Sachot C, Poole S, Luheshi GN (2006) Circulating interleukin-6 induces fever through a STAT3-linked activation of COX-2 in the brain. Am J Physiol Regul Integr Comp Physiol 291:R1316-R1326

Saper CB, Romanovsky AA, Scammell TE (2012) Neural circuitry engaged by prostaglandins during the sickness syndrome. Nat Neurosci 15:1088-1095

Schneider K, Klaas R, Kaspers B, Staeheli P (2001) Chicken interleukin-6: cDNA structure and biological properties. Eur J Biochem 268:4200-4206

Simm B, Ott D, Pollatzek E, Murgott J, Gerstberger R, Rummel C, Roth J (2016) Effects of prostaglandin E2 on cells cultured from the rat organum vasculosum laminae terminalis and median preoptic nucleus. Neuroscience 313:23-35 
Simon E, Pierau FK, Taylor DCM (1986) Central and peripheral thermal control of effectors in homeothermic temperature regulation. Physiol Rev 66:235-300

Sköld-Chiriac S, Nord A, Tobler M, Nilsson J-A, Hasselquist D (2015) 2015. Body temperature changes during simulated bacterial infection in a songbird: fever at night and hypothermia during the day. J Exp Biol 218:2961-2969

Staeheli P, Pühler F, Schneider K, Göbel T, Kaspers B (2001) Cytokines of birds: conserved functions - a largely different look. J Interferon Cytokine Res 21:993-1010

Steiner AA, Ivanov AI, Serrats J, Hosokawa H, Phayre AN, Robbins JR, Roberts JL, Kobayashi S, Matsumura K, Sawchenko PE, Romanovsky AA (2006) Cellular and molecular bases of the initiation of fever. PLos Biol 4:e284

Töllner B, Roth J, Störr B, Martin D, Voigt K, Zeisberger E (2000) The role of tumor necrosis factor (TNF) in the febrile and metabolic responses of rats to intraperitoneal injection of a high dose of lipopolysaccharide. Pflügers Arch Eur J Physiol 440:925-932

Viertlboeck BC, Hanczaruk MA, Amann B, Bader SR, Schmitt R, Sperling B, Schwarz SCN, Schmahl W, Deeg CA, Göbel TW (2013) Chicken immunoregulatory Ig-like receptor families: an overview and expression details on ggTREM-A1. Develop Comp Immunol 41:403-412

Xin L, Blatteis CM (1992) Hypothalamic neuronal responses to interleukin-6 in tissue slices: effects of indomethacin and naloxone. Brain Res Bull 29:27-35

Publisher's Note Springer Nature remains neutral with regard to jurisdictional claims in published maps and institutional affiliations. 